\title{
The IAB Job Vacancy Survey: design and research potential
}

\author{
Mario Bossler ${ }^{1}$, Nicole Gürtzgen², Alexander Kubis ${ }^{3}$, Benjamin Küfner ${ }^{1 *}$ (D) and Benjamin Lochner ${ }^{4}$
}

\begin{abstract}
This article provides an overview of the IAB Job Vacancy Survey and its research potential. The IAB Job Vacancy Survey is a quarterly establishment survey covering the (un-)satisfied labor demand in Germany. This survey identifies the entire number of vacancies on the German labor market, including those vacancies that are not reported to the Federal Employment Agency. The main questionnaire obtains information about the number and structure of vacancies, future labor demand, the current economic situation and the expected development of participating establishments. In addition, the questionnaire collects information about the last new hiring and the last case of a failed recruitment process. Finally, the questionnaire enquires about employer attitudes and firms' use of current labor market instruments. The Research Data Centre of the German Federal Employment Agency offers access to the data starting from the survey waves 2000 onwards.
\end{abstract}

Keywords: Vacancies, Labor demand, Recruitment, Job vacancy survey, Establishments

JEL Classification: J23, J6

\section{Introduction}

Despite its key role in labor market processes, the demand side of the labor market is still viewed as a black box in most empirical labor market research. This is primarily due to a lack of suitable micro-data: While individual-level data characterizing individuals' behavior have been used extensively in economic and sociological labor market research, there are considerably fewer comparable, high-quality, representative data sets on employers' labor demand. When measuring labor demand, researchers typically face two data limitations. First, data on realized employment provide an incomplete picture of labor demand, as realized employment levels fail to account for unmet labor demand, in the form of unfilled vacancies. Second, even if administrative data on vacancies are available, these data are often confined to vacancies that are registered with public employment agencies, which only cover a certain percentage of all vacancies (Fig. 1).

*Correspondence: benjamin.kuefner@iab.de

${ }^{1}$ Institute for Employment Research, Nuremberg, Germany

Full list of author information is available at the end of the article
In this article, we present one of the few data sets that provides information on the structure and level of both met and unmet labor demand: The IAB Job Vacancy Survey (IAB JVS). The objective of the IAB JVS, which has been carried out by the Institute for Employment Research (IAB) since 1989, is twofold: The first goal is to provide comprehensive information on the structure and number of registered and unregistered vacancies in the German labor market (for an earlier description, see Kettner et al. 2011). As such, the survey is also part of the official European Job Vacancy Statistics, managed by Eurostat, providing a full picture of vacancies in Germany. Figure 1 illustrates the relevance of collecting information on both registered and unregistered vacancies by displaying the share of registered vacancies in the overall number of vacancies in Germany. In Germany, as in many other countries, establishments are not legally obliged to report their job vacancies. Thus, the Federal Employment Agency (FEA) statistics only include part of the aggregate vacancies, i.e. the number of reported vacancies for which employers have used the services of 


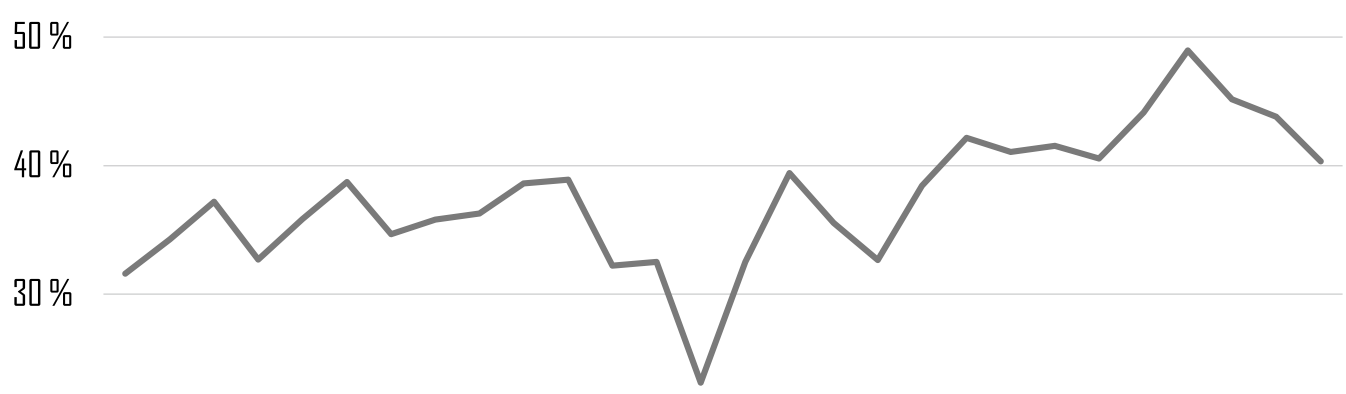

$20 \%$

$10 \%$

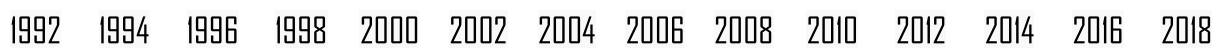

Fig. 1 Share of registered job vacancies, 1992-2019. Job vacancies for which the federal employment agency has a contract with/assignment from an establishment to find a match for. Source: IAB JVS, fourth quarter

the FEA. Figure 1 demonstrates that the fraction of registered vacancies in all vacancies ranged between 23 and 49 percent over the last three decades for Germany.

Due to the variation in the share of registered job vacancies in all vacancies over time (Fig. 1), the entire labor demand cannot be reliably derived from registered job vacancies. Registered vacancies represent aggregate vacancies neither in their structure nor in their volume (Yashiv 2007; Jackman et al. 1989; Kettner and Stops 2009), and this may change over time. Brenzel et al. (2016) state that "the decision of using public placement services by FEA is influenced by many factors, not least by soft factors, such as the establishments' satisfaction with the local employment agency. The required qualification level is also important." For jobs with complex tasks, the placement services by the FEA are used less often (Kettner and Stops 2009).

The second goal of the survey is to offer detailed information on employers' search and recruitment processes. In doing so, the survey aims to fill a notable gap in microdata availability, as other data sets characterizing employers' recruitment behavior in a comparable manner are scarce.

With the help of the Research Data Centre (FDZ) of the German Federal Employment Agency, the IAB JVS has been available to the scientific community since 2010 . This article aims to provide interested users and those interested in existing studies based on the survey with an overview of the IAB JVS and its research potential. The remainder of this article is structured as follows. Section 2 gives an overview of the questionnaire and methodological issues, such as response behavior and the sampling and weighting procedures. Section 3 introduces the most recent developments in terms of opportunities to link the survey to administrative data sources. Section 4 addresses the research potential of the IAB JVS by first describing the survey's role in the European Vacancy Statistics and, second, by comparing the IAB JVS to related surveys from other countries. Finally, Sects. 5.1 and 5.2 provide a brief overview of existing substantive and survey methodological research before Sect. 6 concludes.

\section{Dataset description \\ 2.1 Sample}

The IAB JVS comprises a repeated cross-section of German establishments. The population of the main survey in the fourth quarter of every year consists of all establishments in Germany with at least one employee subject to social security contributions. Because the share of establishments reporting open vacancies tends to be small, the survey requires a large sample. ${ }^{1}$ For the IAB JVS, a stratified random sample of 110,000 establishments is drawn anew every year from the population of establishments, which is about 2,200,000 establishments. This means that every year about five percent of all establishments are invited to participate. Since the fourth quarter of 2015, the sample has been stratified by region (West and East Germany), six establishment size classes and 24 industries based on the German classification of

\footnotetext{
${ }^{1}$ In the IAB JVS, the employment-weighted share of establishment reporting zero vacancies is $71.7 \%$ in the years 2010 to 2019 . For the U.S., Davis et al. (2013) report 45.1 percent in their monthly JOLTS data from 2001 to 2006. This difference between Germany and the US can be explained by various reasons: (i) the large number of small establishments in Germany, or (ii) relatively lower turnover rates in Germany (Bossler and Upward 2016).
} 
industries 2008 (NACE rev. 2), creating a three-dimensional sampling matrix. ${ }^{2}$ The contact probability varies strongly within each stratification cell. For example, the probability to be sampled is almost 100 percent for large establishments with more than 1000 employees in the agricultural sector, while the probability of small establishment in the retail sector is only 0.5 percent.

Since 2006, phone interviews have complemented the comprehensive written questionnaire. Specifically, in the subsequent three quarters, a randomly chosen subset of the respondents from the written survey is asked to update part of the survey information. To maintain a high response rate, the phone survey focuses only on a few key questions on vacancies and employment. This process creates an intra-annual panel of four waves.

\subsection{Content of the survey}

The IAB JVS surveys human resources managers or executives with personnel responsibility. Respondents are asked to provide information on the number and structure of vacancies, recruitment processes and developments relevant to labor market policies. The survey is conducted annually in the fourth quarter by a paper and pencil questionnaire along with an online response option.

The questionnaire used in the 4th quarter consists of three modules. The first module, the so-called main questionnaire, obtains information about the number of employees, the workforce composition and the number and structure of vacancies. Furthermore, the establishments are asked about their current economic situation, hirings and separations during the last 12 months and their expectations regarding future labor demand. Questions about industrial relations complete the main questionnaire.

The second module of the questionnaire obtains information on topics that vary from wave to wave. In general, this module collects information on employers' assessment and use of specific labor market instruments. Furthermore, this part also includes questions about employers' willingness to hire individuals with specific sociodemographic characteristics, such as long-term unemployed individuals or migrants.

The last module of the questionnaire covers the most recent successful hiring process and the most recent recruitment failure. This module collects detailed information about the hired employee, predetermined characteristics of the open position and detailed information on the search process. For example, this part of the survey asks employers to provide precise information on the recruitment duration, that is the duration from the start of the search until a decision was made regarding an applicant. Further questions refer to the search channels the employers adopt relating to the most recent hiring process, such as social networks, newspaper ads, private and public employment agencies and the use of companies' websites and online job boards. Both the main questionnaire and the last module on hiring processes and recruitment failures are, except for minor changes, stable over time and may therefore provide insights into the development of the topic of interest.

In summary, the IAB JVS provides detailed and extensive information on the following topics ${ }^{3}$ :

- Number and structure of vacancies and labor demand

- Overall economic condition in the surveyed establishments

- Information on recruitment processes and the instruments used for recruitment

- Employers' utilization and assessment of labor market programs

- Information on current topics regarding labor market policy

- Extent, causes and establishment-level effects of recruitment failures.

\subsection{Contact and responses to the written survey in the fourth quarter}

All establishments in the sample are contacted by mail at the beginning of October and are asked to participate in the survey. The IAB JVS is conducted by Economix Research \& Consulting, which is commissioned by the IAB. The mailing includes a cover letter, a privacy/ data protection statement, the questionnaire and a sheet with instructions on how to fill out the questionnaire and answers to frequently asked questions. The first deadline for completing the questionnaire is the end of October. A few weeks later, a second mailing includes the same content as well as a cover letter reminding recipients to participate. In this letter, the final deadline, the end of December, is noted.

The analysis of response behavior over time shows that the number of daily responses clearly decreases before the first deadline (Fig. 2). A similar response pattern is observed before the second and final deadline. Despite the deadline at the end of December, we experience a

\footnotetext{
${ }^{2}$ Until the third quarter of 2015, the annual samples were stratified by region, by 23 economic sectors and seven establishment size classes.
} 


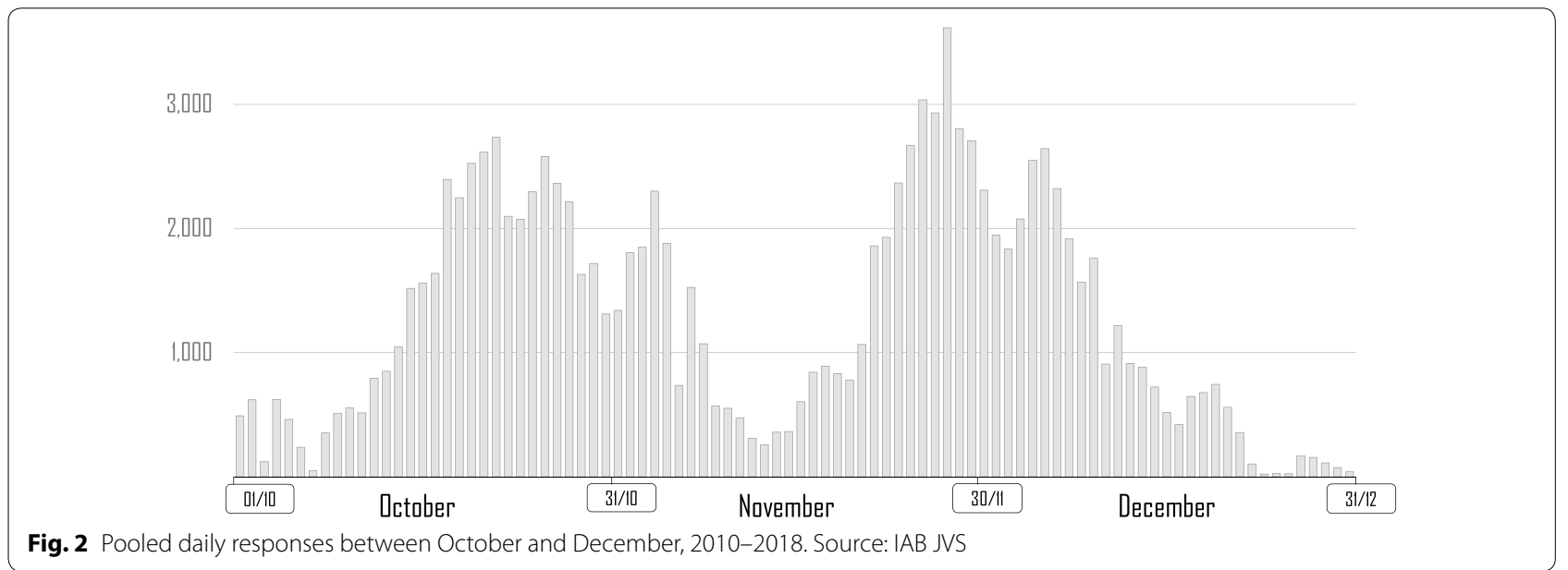

natural deadline due to the Christmas holidays. The number of responses during the last week of December is typically negligible. Figure 2 illustrates that the reminder contributes to reaching a broader basis of respondents with two peaks during the 4th quarter. Overall, the reminder leads to a considerable increase in the number of responses, as during the past 8 years, approximately 60 percent of the responses did not occur before 31 October. These patterns are therefore suggestive of a positive effect of the reminder on response rates for establishment surveys in line with Snijkers and Jones (2013).

In total, between 11,600 and 15,100 establishments (Fig. 3) were successfully surveyed between 2010 and 2018, and approximately 9000 took part in the quarterly phone survey. As a result, the mean response rate is approximately 16 percent in this period, and for the subsequent phone interviews, approximately 90 percent of previous participants were willing to participate.

\subsection{Survey mode}

Since 2002, establishments have also been given the option to fill out an online questionnaire that is identical to the paper and pencil version. At the beginning of 2002, the fraction of online participants in all respondents was 9 percent; this increased to 18 percent in 2011. During recent years, the fraction of establishments responding online has been steadily increasing and has currently reached 39 percent (Fig. 3). Thus far, the experience suggests that especially for small establishments (which often do not have their own website) a sufficient fraction can be reached only with a paper and pencil and a telephone survey. This is of major importance, as in Germany more than 75 percent of all establishments have fewer than 10 employees, representing 15 percent of all employees. Thus, for this group, paper and pencil

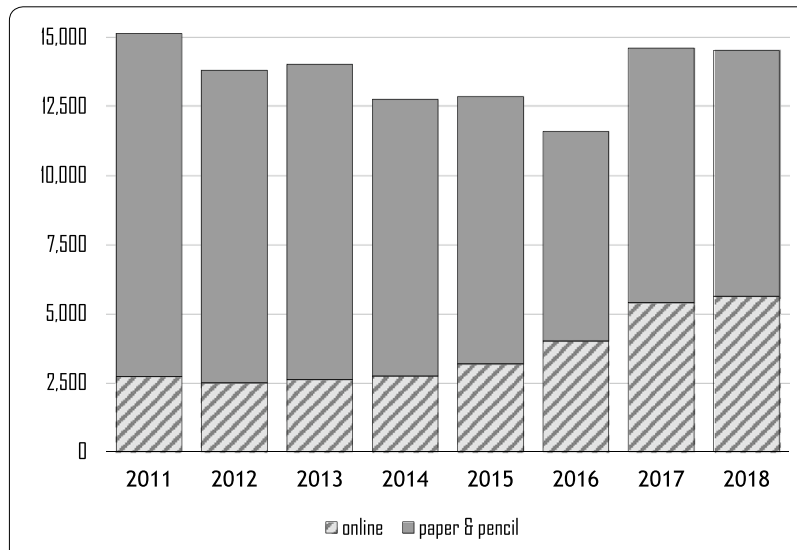

Fig. 3 Online and paper and pencil responses, 2011-2018. Source: IAB JVS

and telephone surveys are likely to remain relevant in the future to ensure a sufficient number of observations from this size class. ${ }^{4}$

\subsection{Extrapolation procedure used for the main survey in the fourth quarter}

Because the sampling design of the IAB JVS involves a disproportionate stratified sampling procedure, there are strata that are over- or underrepresented in the raw data. For this reason and because of a potential response bias, establishments' responses need to be extrapolated in order to calculate statistics that are representative of the German population of establishments. In particular, the responses of participating establishments are extrapolated using a generalized regression estimator (GREG) for the level of the entire German economy. The

\footnotetext{
${ }^{4}$ To assess these issues in a more systematic manner, an ongoing research project is exploring the effect of the survey mode on establishments ' response behavior by using an experimental set-up.
} 
procedure incorporates both design and nonresponse weights, allowing for statements regarding the development of labor demand and recruitment processes that are representative of the respective industries, regions and size classes. Details on the current extrapolation procedure may be found in Brenzel et al. (2016). To compute the establishment weights, the following steps are taken:

1 The design weights are computed for every cell of the sampling matrix as the inverse of the respective sampling ratio.

2 The design weights are multiplied by a weight computed from a nonresponse model. The latter is based on a logistic regression model using the establishment size category, industry, average daily wage and average employee age from administrative data of the Federal Employment Agency as auxiliary variables. The nonresponse weight is the inverse of the estimated response propensity.

3 The weights from step 2 are used as the starting weights to calibrate the weights based on a GREG estimator with the aim of exactly matching the anchor variables "number of establishments" and "number of employees subject to social security contributions" in all cells of the sampling matrix.

Because information on the anchor variable "number of employees subject to social security contributions" is available only with a time lag of 18 months, this variable needs to be estimated for the timely extrapolation of the most recent survey wave. Once the updated employment figures from the Employment Statistics Register of the Federal Employment Agency are available, the calibration procedure is repeated after 18 months, resulting in a revised set of extrapolation weights. The data that are available at the FDZ contain the raw unweighted data along with the revised weights. As a consequence, every new wave of the survey is made available in the FDZ no earlier than 18 months after the end of the field phase. Previously published results by the IAB in the form of press releases and policy reports usually rely on preliminary weights, which is why they cannot be exactly replicated using FDZ data based on the revised weights. However, the differences usually lie within the respective 95 percent confidence interval.

Because the sampling frame has slightly changed after the third quarter in 2015, the retrospective application of the new extrapolation procedure to the 2000 to 2014 waves requires a recoding of the different establishment size categories and industry classifications of the sampling matrices prior to the fourth quarter in 2015 (see Sect. 2.1).

\subsection{Telephone surveys in the first, second and third quarters of every year}

Short follow-up surveys by phone on core questions are conducted during the three subsequent quarters for a subset of participants of the main survey. These phone surveys complement the written main survey in the respective fourth quarter and obtain and update the most important information from the main questionnaire, including the number of employees, the assessment of current workforce developments and the number of vacancies. These interviews last on average $5 \mathrm{~min}$.

In each subsequent quarter, a subsample of establishments is drawn from the set of participants in the written main questionnaire distributed in the fourth quarter. The target sample size of establishments is 9000 per quarter. The net sample of the written main survey therefore constitutes the gross sample of the follow-up surveys by phone. For each of the three subsequent quarters, the respondents receive a quarter-specific establishment weight that results from the establishment weight of the main survey in the fourth quarter and a nonresponse correction for the respective subsequent quarter.

\section{Record linkage}

To answer specific research questions, to validate the data quality, or to counteract measurement error, it is beneficial to complement the data from the IAB JVS with additional administrative information. Since 2010, all surveyed establishments, by accepting IAB's data protection declaration, have consented to linking their survey data to existing IAB administrative data. ${ }^{5}$ Due to a oneto-one mapping of surveyed establishments to unique establishment identifiers, the IAB JVS can be linked to several IAB datasets.

To date, the FDZ offers two datasets that can be combined with the IAB JVS: The Establishment History Panel (BHP) and the Administrative Wage and Labor Market Flow Panel (AWFP).

The BHP contains all establishments with at least one employee liable to social security on the reference date of June 30th. The BHP contains information about the industry and the location of the establishments. Furthermore, it reports the number of employees liable to social security and marginal part-time employees by gender, age, occupational status, qualification and nationality. In addition, information about worker flows, foundations and closures of establishments are available on request.

The AWFP is a dataset on labor market flows and stocks for the universe of German establishments. The

${ }^{5}$ In 2009, a subset of establishments directly consented to link their information. 
AWFP contains information on job flows, such as job creation and destruction, worker flows, and wages. In addition, it compiles this information for segments of the labor force according to various employee characteristics and for some subgroups of employees. The AWFP-JVS contains all establishments surveyed by the IAB JVS in the years 2010-2014.

There may be research questions that require the employment history of the most recent hire, both prior to and after the hiring process. Unfortunately, any worker identifier that would allow for linking data to existing administrative data is not available in the IAB JVS. An algorithm that attempts to fill this gap is presented in Lochner (2019). This algorithm uses information that is present in both the survey data as well as in the administrative records and performs several steps to combine both datasets. More precisely, the algorithm identifies the exact job interval in the Integrated Employment Biographies (IEB) that is related to the hire that is reported in the IAB JVS's case of most recent hirings. With its default parameterization, the algorithm finds approximately 70 percent of hires that can be merged. The link to the IEB allows researchers to combine the information on the hiring process and the workers' full (un)employment history from the administrative data (IEB).

\section{Potential of the German IAB job vacancy survey \\ 4.1 The survey as a part of the European job vacancy statistics}

The IAB JVS provides official statistics since it is the German part of the European Job Vacancy Statistics. Each country in the European Union (EU) is obligated to collect the representative number of job vacancies in the labor market each quarter. These data have a legal foundation in an EU regulation that addresses the fundamentals of data comparability. The regulation also mandates the definition of vacancies in the survey, as follows:

"A paid post that is newly created, unoccupied, or about to become vacant, (a) for which the employer is taking active steps and is prepared to take further steps to find a suitable candidate from outside the enterprise, and (b) which the employer intends to fill either immediately or within a specific period of time." (European Commission 2008).

The definition of a vacancy is precise and equal across countries, e.g. requiring that vacancies are only recorded if they are intended to be filled from outside the enterprise. However, the explicit wording of survey questions is not equal across countries, which may be a drawback for cross-country comparisons. In addition to the definition of vacancies, the EU regulation also requires information to be collected from local units of enterprises, covering all establishments in the territory of Germany. Moreover, the data should cover all regular employees across all industries and all establishment size categories. In addition to vacancies, the European Job Vacancy Statistics include the number of filled positions as indicated by the IAB JVS, which is the overall number of employees.

Each country manages its own survey to collect these data, and countries are mandated to report the weighted total number of vacancies and employees within 45 days after the end of each quarter. Vacancy rates for all EU-28 member states are provided by Eurostat's online database.

The data can be used for cross-country comparisons, e.g., to calculate and compare the total number of job vacancies across European countries or to calculate the contribution of each country's vacancies to the overall number of vacancies in Europe. Most importantly, it is possible to compare the matching efficiency of the labor markets across European countries by illustrating the data in Beveridge curves.

The efficiency of matching, where matching is defined as unemployed individuals filling vacant positions, can be described by the Beveridge curve, which relates the unemployment rate with the vacancy rate in a labor market over time. If a labor market moves right along the Beveridge curve, unemployment increases along with a decreasing vacancy rate, which could be the result of a recession without a loss or gain of efficiency in the matching process. By contrast, if a market moves left along the Beveridge curve, it is in a period of labor market recovery. If the unemployment rate decreases along with the vacancy rate, the Beveridge curve shifts inward, implying a more efficient matching of unemployed to vacant positions. This could be a result of decreased mismatch between the unemployed individuals and vacancies, where mismatch can be due to discrepancies in general education or occupational training. Another reason for an inward shift could be decreasing labor market frictions leading to a faster matching of unemployed individuals and vacancies.

Figure 4 illustrates the Beveridge curve for Germany and the EU-28 states over the last decade. This figure shows an outward shift in Europe early in the decade (2010-2013), which corresponds in time with the sovereign debt crisis in the Euro-Area, implying an efficiency loss in the matching of unemployed individuals to vacancies in the European labor market, which is not observed for Germany. In the following years, the EU member states' labor markets moved left along the Beveridge curve, implying a labor market recovery with some efficiency gains as the Beveridge curve evolved towards lower unemployment while there 


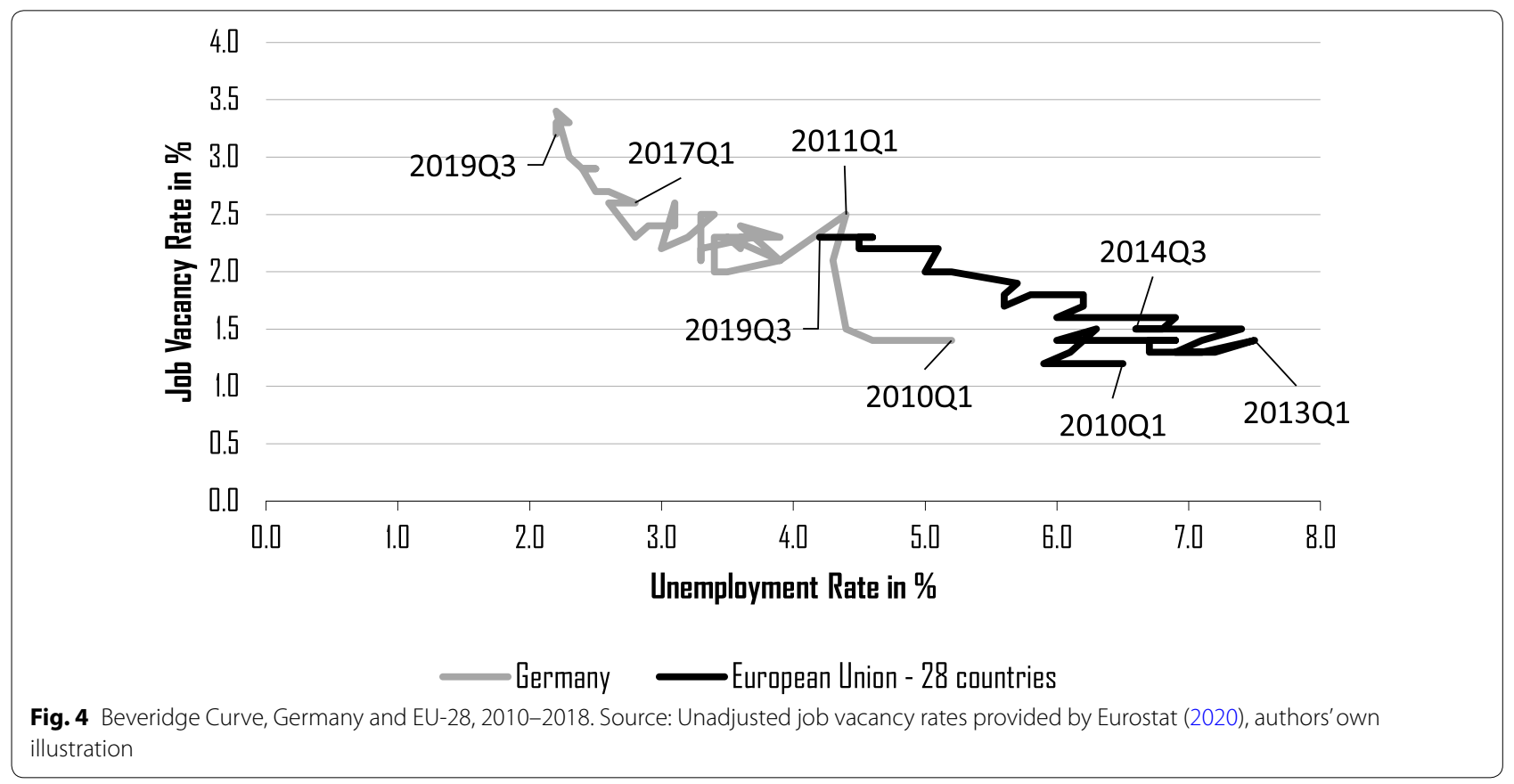

was only a modest countermovement in the vacancy rate. In Germany, the labor market appears to have become tighter in recent years, since the vacancy rate substantially increased along with a slight reduction in unemployment.

\subsection{Comparison to other vacancy studies}

While Eurostat regulates the collection of information on vacancies within Europe, each country's national statistical agency conducts its own data collection. Outside the EU, some states, including Switzerland and Norway, participate in Eurostat's data collection as adjunct members of the European data collection. However, information on job vacancies is also collected in other large countries outside Europe, such as the United States, Australia, and Canada.

Since 1999, the US Bureau of Labor Statistics has been gathering vacancy data with the Job Opening Labor and Turnover Survey (JOLTS). To enable comparisons with the unemployment rate over the same period, the JOLTS asks companies about the number of vacancies each month. This is a major difference from the European Job Vacancy Statistics, where data on vacancies are available on a quarterly basis. In addition, the definition of a job opening differs. For the JOLTS, only job openings with start dates within the next 30 days are taken into account, while the European Job Vacancy Statistics also considers vacancies that ought to be filled later in the future. According to both surveys, positions for temporary agency employees and internal job advertisements do not contribute to the number of vacancies. Similar to the IAB JVS, the JOLTS also collects data on worker flows, including information on hirings and separations (Mueller and Wohlford 2000).

Another example of a national vacancy survey with a long tradition is the Australian Job Vacancy Survey. With a few brief exceptions, it has been examining the labor demand in Australia since 1974 (Australian Bureau of Statistics 2020). Until 2019, Statistics Canada collected data on vacancies in two separate surveys, the Job Vacancy and Wage Survey (JVWS) and the Job Vacancy Statistics as part of the Business Payrolls Survey (BPS). Since then, the JVWS has been the only vacancy survey in Canada (Statistics Canada 2020a). The JVWS is a quarterly survey of persons responsible for human resources in various locations that obtains information on vacancies and wages. This survey has similarities with the IAB JVS in terms of the definitions used. For example, the JVWS does not specify the time span within which vacancies are supposed to be filled, and subcontractors are excluded. Since survey participation is mandatory for all employers, the response rate is very high at 88 percent (Statistics Canada 2020b).

While many national surveys collect vacancy information with slightly different research designs and definitions of job vacancies, they produce comparable vacancy statistics that show similar trends over time. A comparison of the vacancy rates in the JOLTS data and the IAB JVS data illustrates this (Fig. 5). The vacancy rate relates the number of vacancies to the total number of vacancies 


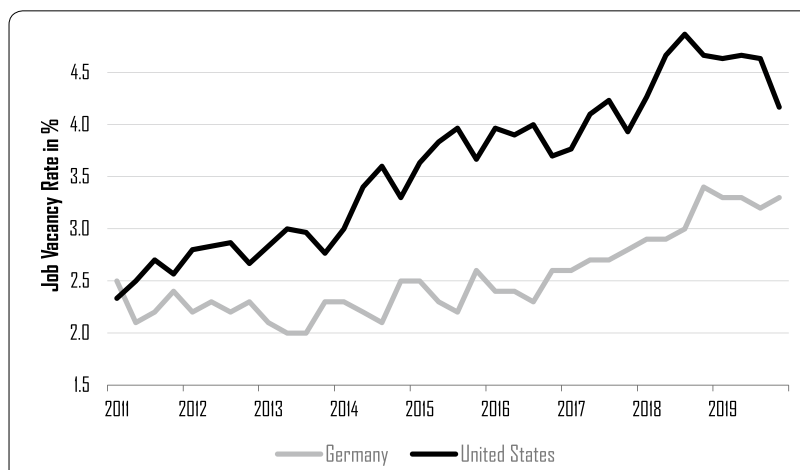

Fig. 5 Vacancy rate, Germany and United States, 2011-2019. Source: Unadjusted job vacancy rates of the German JVS, as provided by Eurostat (2020), and job vacancy rates of the JOLTS, as provided by the US Bureau of Labor Statistics (2020), author's own illustration

and employees and is therefore a measure that can be easily compared across different countries. In both countries, the vacancy rate increased during the economic boom between 2010 and 2019. The increase in the US vacancy rate is higher than that of the German rate, with the vacancy rate reaching its peak in both countries at the end of 2018. However, after 2018, the vacancy rate stagnated in Germany and declined in the US. ${ }^{6}$ Note that the number of vacancies and hence the vacancy rates may be triggered by various factors. Mercan and Schoefer (2020) highlight the role of vacancy chains. Quits and subsequent replacement hiring generate vacancies and these vacancies beget other vacancies. This amplification effect should be larger in economies with higher worker turnover. Worker turnover is smaller in Germany than in the US (see Bossler and Upward 2016; Bachmann et al., 2020) and this difference intuitively results in a difference in vacancy rates. Another contributing factor may be differences in the industry composition. Davis et al. (2013) show that in the U.S. the vacancy rate is highest in the service sector, where it is roughly twice as high as in the manufacturing sector. The same is true for Germany. However, in the U.S. the manufacturing sector has decreased dramatically since the $80 \mathrm{~s}$, whereas in Germany it has been relatively stable (see Lochner et al. 2020).

One important difference that distinguishes the IAB JVS from other surveys is that the IAB JVS aims to provide representative vacancy statistics and is designed for scientific purposes. Therefore, the survey is complemented by a great deal of background information by means of record linkage (see Sect. 3) and the additional modules of the questionnaire. This added information

\footnotetext{
${ }^{6}$ In addition, Bauer (2015) showed that the great recession of 2009 affected vacancies in Germany as well as in the US.
}

enables the users of the IAB JVS to explore the structure, developments and correlations of job vacancies in greater depth than is possible with most other job vacancy surveys.

The collection of data on the last successful hiring process and the last recruiting failure is a unique feature of the IAB JVS. As far as we know, there is no comparable employer study worldwide that provides information on the characteristics of the hiring process by considering the time-series dimension. Although other studies such as the Employment Opportunities Pilot Project (EOPP) (see Barron et al. 1985), the Multi-City Study of Urban Inequality (MCSUI) (see Holzer 1999) and the Survey of Employers' Recruitment Practices (SERP) (see Pellizzari $2011)^{7}$ have similar contents, none of these studies was designed to provide a repeated cross-section of data, as the IAB JVS is. These data sets are cross-sectional with a maximum of two waves and provide insights into recruitment procedures used at the time of the survey. Unlike these data sets, the IAB JVS makes it possible to analyze secular developments, such as changes in employers' search channels as the internet has become increasingly available. Furthermore, almost all of the abovementioned studies were carried out before $2005^{8}$ and do not cover more recent time periods.

\section{Results and discussion}

\subsection{Research on employers' search and recruitment processes}

Given the lack of microdata on employers' search processes, the IAB JVS offers great opportunities to study research questions that have not been addressed so far in the literature. Because the data have recently become increasingly available to the (international) scientific community, the last few years have seen a surge of empirical studies that have used the IAB JVS to study a variety of topics. Below, we give a brief overview of these studies.

Some of the first natural outcomes when using the data are the length and pattern of recruitment and vacancy durations. One of the first studies was conducted by Davis et al. (2014), who document that recruitment and vacancy durations vary greatly across occupations. The authors also provide evidence of longer recruitment durations in Eastern Germany and in larger firms and shorter recruitment durations under slack labor market

\footnotetext{
7 In addition, we are aware of the Survey of a large sample of Australian employers, "Offre d'Emploi et Recrutement"-OFER and the Organization of Strategy Labor Market Research (OSA) vacancy survey. Compared to the IAB JVS, all of these surveys have similar drawbacks.

${ }^{8}$ The French study "Offre d'Emploi et Recrutement" is an exception and was conducted from 2005-2006. As there have been major economic and social changes over the last 15 years, this data set fails to cover any recent developments.
} 
conditions. Ehrenfried and Holzner (2019) characterize the pattern of recruitment processes and document that vacancy-filing hazards increase during the planned search period and decrease thereafter. Gürtzgen and Moczall (2020) explore recruitment durations in the context of different search strategies. They exploit information indicating whether employers first formed a pool of applicants from which they chose the most suitable candidate (non-sequential search) or whether they hired the first suitable applicant (sequential search). The authors confirm previous results provided in the literature, indicating that with non-sequential search, vacancy durations are to a great extent selection periods. Rebien (2019) focuses on the role of employee referrals for recruitment durations and shows that referrals are associated with a low incidence of recruitment delays and a shorter duration of delays.

Relatedly, the determinants and implications of employers' adopted search and recruitment channels have attracted great interest from researchers. Rebien et al. (2020) explore the role of firm size in employers' use of informal search and recruitment channels (referrals) versus formal search and recruitment channels. They find that larger firms invest more effort into formal search activities and are less likely to hire applicants via referrals than smaller firms. The authors show that these findings are consistent with the predictions of a search and matching model, in which formal search and recruitment processes are more costly than informal search processes and in which larger and more productive firms can afford to spend more resources on formal search processes than less productive firms.

Gürtzgen et al. (2020) study whether online recruitment, such as recruitment via internet job boards or job postings on companies' websites, improves the quality of the match of new hires. Exploiting the novel linkage between the IAB JVS and IEB employment biographies of the most recent hire (see Sect. 3), the authors explicitly compare the match outcomes of online and nononline recruits. Based on this comparison, they find that online recruiting moderately increases the stability of new matches but has no impact on wages. To propose a possible explanation for this result, the authors further show that online recruiting not only increases the number of applicants and the share of unsuitable candidates per vacancy but also induces employers to post more vacancies.

The studies by Holzner and Watanabe (2019a, b) deal with employers' search via the FEA. Holzner and Watanabe (2019a) address the role of the FEA in reducing search frictions. Using information on the number of applicants and employers 'adopted search channels from the IAB Job Vacancy, the authors show that compared with search via private search channels, the FEA contributes to reducing search frictions by distributing the applications of registered unemployed more evenly among vacancies. In a related study, the authors model employers' decision to use the FEA and argue that employers trade off lower wages due to lower coordination frictions against a potential negative selection of applicants (Holzner and Watanabe 2019b). Lochner et al. (2019) use information on the number of search channels employers adopted-among other things-to operationalize employers' recruitment intensity-a concept that has very recently attracted much interest in the macroeconomic literature.

Other studies examine the role of wage determination in the recruiting process. An example is the study by Brenzel et al. (2014), which analyzes the incidence of wage posting and wage bargaining in the matching process. The authors document that both types of wage determination coexist in the German labor market, with wage posting accounting for about two-thirds of hirings. Wage bargaining is more likely for more-educated applicants and in jobs with special requirements as well as in tight regional labor markets. Gartner and Holzner (2015) address the role of wage posting versus bargaining in attracting suitable applicants. Using data from the IAB JVS, the authors document that the offer to bargain over pay is associated with a lower share of suitable applicants. The authors argue that the evidence is consistent with the predictions of a directed search model, where employers have incomplete information about worker productivity.

A common thread of the studies cited above is that they seek to provide microfoundations for search and matching models without explicitly taking their models to the data. Based on a somewhat different approach, a related strand of literature takes advantage of the IAB JVS to explicitly estimate or calibrate search and matching models. For example, Hochmuth et al. (2019) build up a search and matching model that seeks to explain the decline in unemployment after the German Labor Market (Hartz) Reforms. They use the IAB JVS to quantify the extent to which employers have become less selective in hiring after the Hartz Reforms. Carbonero and Gartner (2020) exploit information on search costs from the last hiring process to assess the relative importance of fixed costs versus variable search costs. Based on their empirical results, the authors calibrate a search and matching model to quantify the extent to which fixed search costs can amplify business cycle fluctuations.

Carillo-Tudela et al. (2020) develop a quantitative competitive search model with heterogeneous firms and match-specific productivity in which firms decide about recruiting intensity, hiring standards and wage offers. The authors calibrate their model using data from the IAB 
JVS to assess the relative importance of these recruitment dimensions for the variation in job-filling rates across firms, as well as for the variation in matching efficiency across local labor markets.

Van den Berg and Foerster (2019) develop a search and matching model with multiple applications and vacancy referrals. Their model accounts for crowding-out effects in the hiring process, as a vacancy referral increases the reemployment probability of the job searcher receiving it but has a negative externality on all other job searchers. Next to using individual-level data, the authors use the IAB JVS to structurally estimate their model and to simulate a variety of policy changes.

Mercan and Schoefer (2020) incorporate the role of and replacement hiring into a search and matching model that distinguishes between short-lived workerfirm matches and longer-lived jobs that persist even after a given match dissolves. In their model, job resignations quits trigger vacancies, which in turn create further vacancies through replacement hiring. The authors use the IAB JVS, among other data sources, to calibrate their model and to quantify how vacancy chains may amplify business cycles.

While this summary of most recent substantive research highlights the survey's research potential, it also shows that the latter has not yet been fully exhausted, as there are many research topics left for future research. In addition to the questions addressed above, the data may be used to understand a variety of other labor market issues, for example, how employers respond to technological change and whether employers have preferences for discrimination.

\subsection{Survey methodological research}

In addition to providing data for substantive research on vacancies and hiring procedures, the IAB JVS is the subject of survey methodological research. The latter not only contributes to advances in the relatively unexplored field of establishment survey methodology but also helps to secure and improve the data quality. One example is an ongoing project analyzing unit-nonresponse in the IAB JVS, which poses a risk for nonresponse bias. Using a rich administrative data set on all employing establishments, this project evaluates the development of this bias in the long run. Furthermore, the project not only seeks to test more theory-driven hypotheses but also to build data-driven models based on machine learning to test for deeper interactions and more complex nonresponse patterns.

The advantages of experimental variation can be used for substantive (e.g., Bossler et al. 2020) and methodological research. An additional survey based on the respondents of the IAB JVS (Vicari and Zmugg 2015) examined, among other things, the influence of the placement of a consent question regarding record linkage and consent bias. The results of this study show that a question for consent to record linkage should be placed at the beginning of a questionnaire rather than at the end. This change would yield higher consent rates and a decrease in consent bias (Sakshaug and Vicari 2018). Another experiment varied multiple contact mode strategies between classical mail and email in an additional survey of the IAB JVS. The findings of this experiment provided causal evidence that the classical mail contact mode achieved the highest response rates and the lowest level of nonresponse bias. The second best solution in the tradeoff of costs, response rate and nonresponse bias is an email invitation followed by a paper reminder. As it has the lowest response rate and the highest level of bias, an email-only contact strategy should be avoided (Sakshaug et al. 2019).

An additional ongoing survey experiment is examining the impact of the instructions on specific item nonresponse rates for questions on search and vacancy durations. For this research project, an additional stratified sample was drawn, and one-half of the observations per cell were assigned to a treatment and a control group. All establishments in the treatment group were given additional instructions for all of the search and vacancy duration questions, while for the control group, only the questions were displayed, without any further instructions. Apart from the survey mode, everything else was identical to the main study. Next to the effect of instructions on item response, we expect the study to deliver interesting insights into the effects of instructions on the duration of the question answering period and specific item nonresponse bias.

\section{Conclusion}

This article provides an overview of the IAB Job Vacancy Survey (IAB JVS). The objective of the IAB JVS, which has been carried out by the Institute for Employment Research (IAB) since 1989, is twofold: The first goal is to provide comprehensive information on the structure and number of registered and unregistered vacancies in the German labor market. As such, the survey is also part of the official European Job Vacancy Statistics. The second goal of the survey is to offer detailed information on employers' search and recruitment processes. In doing so, the survey aims to fill a notable gap in microdata availability, as other data sets characterizing employers' recruitment behavior in a comparable manner are scarce. With the help of the Research Data Centre (FDZ) of the German Federal Employment Agency, the IAB JVS has been available to the scientific community since 2010 . This article provides interested users and those who are 
interested in empirical findings based on the survey with an overview of the IAB JVS and existing works. In this paper, we describe the content of the questionnaire and discuss methodological issues, such as response behavior and the sampling and weighting procedure. We also present the most recent developments of the opportunities to link the survey to administrative data sources. The rich set of available variables along with the opportunities to link the IAB JVS to administrative establishment and individual-level information makes the survey ideally suited to study all issues related to labor demand, recruitment processes and their implications for matching outcomes. While our summary of most recent research highlights the survey's research potential, it also shows that the latter has not yet been fully exhausted, as there are many research topics left for future research.

\begin{abstract}
Abbreviations
AWFP: Administrative Wage and Labor Market Flow Panel; BHP: Establishment History Panel; BPS: Business Payrolls Survey; EOPP: Employment Opportunities Pilot Project; EU: European Union; FEA: Federal Employment Agency; FDZ: Research Data Centre; GREG: Generalized regression estimator; IAB: Institute for Employment Research; IAB JVS: IAB Job Vacancy Survey; IEB: Integrated Employment Biographies; JOLTS: Job Opening Labor and Turnover Survey; JVWS: Job Vacancy and Wage Survey; MCSUI: Multi-City Study of Urban Inequality; OFER: Offre d'Emploi et Recrutement; OSA: Organization of Strategy Labor Market Research; SERP: Survey of Employers' Recruitment Practices.
\end{abstract}

\section{Acknowledgements}

Not applicable.

\section{Authors' contributions}

The manuscript is a joint work of MB, NG, AK, BK and BL. All authors read and approved the final manuscript.

\section{Funding}

The authors have nothing to declare in terms of funding.

\section{Availability of data and materials}

Due to data confidentiality restrictions, the IAB JVS cannot be made available in a repository, but researchers can access the IAB JVS via the FDZ.

\section{Competing interests}

$M B, N G, A K$ and $B K$ are responsible for production, data quality management and publication of the IAB Job Vacancy Survey. All authors contributed to the record linkage of the IAB JVS and their publication via the FDZ.

\section{Author details}

${ }^{1}$ Institute for Employment Research, Nuremberg, Germany. ${ }^{2}$ Institute for Employment Research, University Regensburg, Centre for European Economic Research, Nuremberg, Germany. ${ }^{3}$ Institute for Employment Research, Halle Institute for Economic Research, Nuremberg, Germany. ${ }^{4}$ Institute for Employment Research, University Erlangen-Nuremberg, Nuremberg, Germany.

Received: 6 April 2020 Accepted: 23 September 2020

Published online: 13 October 2020

\section{References}

Australian Bureau of Statistics: Job Vacancy Survey. https://www.abs.gov.au/ ausstats/abs@.nsf/dossbytile/C4AF02FEA6BDAD89CA256BD00026D9 32?OpenDocument (2020). Accessed 19 Aug 2020

Bachmann, R., Bayer, C., Merkl, C., Seth, S., Stüber, H., Wellschmied, F.: Worker Churn and Employment Growth at the Establishment Level. J. Monetary Econ. (2020, in press)

Barron, J., Bishop, J., Dunkelberg, W.C.: Employer search: the interviewing and hiring of new employees. Rev. Econ. Stat. 67(1), 43-52 (1985)

Bauer, K.: Comparison of US and the international labor turnover statistics. Mthly. Labor Rev. 138, 23 (2015)

Bossler, M., Upward, R.: Employee turnover and the expansion and contraction of employers. In: Saridakis, G., Cooper, C. (eds.) Handbook of employee turnover, pp. 305-346. Edward Elgar Publishing, Cheltenham, UK (2016)

Bossler, M., Oberfichtner, M., Schnabel, C.: Employment adjustments following rises and reductions in minimum wages: new insights from a survey experiment. Labour. 34(3), 323-346 (2020)

Brenzel, H., Gartner, H., Schnabel, C.: Wage bargaining or wage posting? Evidence from the employers' side. Labour Econ. 29, 41-48 (2014)

Brenzel, H., Czepek, J., Kiesl, H., Kriechel, B., Kubis, A., Moczall, A., Rebien, M., Röttger, C., Szameitat, J., Warning, A., Weber, E.: Revision of the IAB job vacancy survey: backgrounds, methods and results. IAB-Forschungsbericht. 4 (2016)

Carbonero, F., Gartner, H.: A note on the relation of search costs and search duration for new hires. Macroeconomic Dynamics. 1-14 (2020)

Carillo-Tudela, C., Gartner, H., Kaas, L.: Recruitment intensity, hiring rates and the vacancy yield. Unpublished Manuscript (2020)

Davis, S.J., Faberman, R.J., Haltiwanger, J.C.: The establishment-level behavior of vacancies and hiring. Q. J. Econ. 128(2), 581-622 (2013)

Davis, S. J., Röttger, C., Warning, A., Weber, E.: Job recruitment and vacancy durations in Germany. University of Regensburg working papers in business, economics and management information system. 481 (2014)

Ehrenfried, F., Holzner, C.: Dynamics and endogeneity of firms' recruitment behaviour. Labour Econ. 57, 63-84 (2019)

European Commission: REGULATION (EC) No 453/2008 of the European Parliament and of the Council of 23 April 2008 on quarterly statistics on community job vacancies, Article 2. Official Journal of the European Union. (2008)

Eurostat: Job vacancy Statistics (JVS) database. https://ec.europa.eu/eurostat/ web/labour-market/job-vacancies/database (2020). Accessed 13 Mar 2020

Gartner. H, Holzner, C: Wage posting as a positive selection device: Theory and empirical evidence. CESifo Working Paper. 5494 (2015)

Gürtzgen, N., Moczall, A.: Sequential and non-sequential search among German: Employers-evidence from a Job Vacancy Survey. Appl. Econ. Lett. 27(11), 873-879 (2020)

Gürtzgen, N., Lochner, B., Pohlan, L., van den Berg, G.: Does online search improve the match quality of new hires?. Unpublished Manuscript. (2020)

Hochmuth, B., Kohlbrecher, B., Merkl, C., Gartner, H.: Hartz IV and the decline of German unemployment. A macroeconomic evaluation. In: FAU Discussion Papers in Economics. 01 (2019)

Holzer, H.J.: What employers want: Job prospects for less-educated workers. Russell Sage Foundation, New York (1999)

Holzner, C., Watanabe, M.: Do intermediaries reduce search frictions? Discussion Paper. University of Munich (2019a)

Holzner, C., Watanabe, M.: Understanding the role of the Public Employment Agency. Discussion Paper. University of Munich (2019b)

Jackman, R., Layard, R., Pissarides, C.A.: On job vacancies. Oxford Bull. Econ. Stat. 51, 377-394 (1989)

Kettner, A., Stops, M.: Europäische Betriebsbefragungen über offene Stellen. Ist das Gleiche wirklich gleich? In: Weichbold, M., Bacher, J., Wolf, C. (eds.) Umfrageforschung, pp. 353-372. VS Verlag für Sozialwissenschaften, Wiesbaden (2009)

Kettner, A., Heckmann, M., Rebien, M., Pausch, S., Szameitat, J.: Die IAB-Erhebung des gesamtwirtschaftlichen Stellenangebots - Inhalte. Daten und Methoden. Zeitschrift für Arbeitsmarktforschung. 44, 245-260 (2011)

Lochner, B.: A simple algorithm to link "last hires" from the Job Vacancy Survey to administrative records. In: FDZ Methodenreport. 6 (2019) 
Lochner, B., Merkl, C., Stüber, H., Gürtzgen, N.: A Note on recruiting intensity and hiring practices: Cross-Sectional and Time-Series evidence. In: FAU Discussion Paper in Economics. 4 (2019)

Lochner, B., Seth, S., Wolter, S.: Decomposing the large firm wage premium in Germany. Econ. Lett. 194, 112 (2020)

Mercan, Y., Schoefer, B.: Jobs and matches: quits, replacement hiring, and vacancy chains. Am. Econ. Rev. Ins. 2(1), 101-124 (2020)

Mueller, C., Wohlford, J.: Developing a new business survey: job openings and labor turnover survey at the bureau of labor statistics (2000)

Pellizzari, M.: Employers' search and the efficiency of matching. Br. J. Ind. Relat. 49(1), 25-53 (2011)

Rebien, M.: Employers' search: are employee referrals effective? Econ. Bull. 39(4), 2499-2506 (2019)

Rebien, M., Stops, M., Zaharieva, A.: Formal search and referrals from a firm's perspective. Int. Econ. Rev. (2020, forthcoming)

Sakshaug, J., Vicari, B.: Obtaining record linkage consent from establishments: the impact of question placement on consent rates and bias. J. Surv. Stat. Methodol. 6(1), 46-71 (2018)

Sakshaug, J., Vicari, B., Couper, M.P.: Paper, e-mail, or both?: Effects of contact mode on participation in web survey of establishments. Soc. Sci. Comput. Rev. 37(6), 750-765 (2019)

Snijkers, G., Jones, J.: Business survey communication. In: Snijkers, G., Haraldsen, G., Jones, J., Willimack, D. (eds.) Designing and conducting business surveys, pp. 359-430. John Wiley and Sons, Hoboken (2013)
Statistics Canada: Guide to the job vacancy and wage Survey. https://www. statcan.gc.ca/eng/statistical-programs/document/5202_D1_V1 (2020a). Accessed 19 Aug 2020

Statistics Canada: JVS replacement source of data. https://www150.statcan.gc. ca/n1/pub/75-514-g/75-514-g2019001-eng.htm (2020b). Accessed 19 Aug 2020

U.S. Bureau of Labor Statistics: https://www.bls.gov/data/ (2020). Accessed 18 Aug 2020

van den Berg, G., Foerster, $\mathrm{H}$.: The equilibrium effects of vacancy referrals. Unpublished Manuscript. (2019)

Vicari, B., Zmugg, H.: Die Befragung betriebliche Personalpolitik und offene Stellen: Erhebungsdesign. Befragungsverlauf und Datenqualitätsanalysen. FDZ-Methodenreport. 13, 21 (2015)

Yashiv, E.: Labor search and matching in macroeconomics. Eur. Econ. Rev. 51 1859-1895 (2007)

\section{Publisher's Note}

Springer Nature remains neutral with regard to jurisdictional claims in published maps and institutional affiliations.

\section{Submit your manuscript to a SpringerOpen ${ }^{\circ}$ journal and benefit from:}

- Convenient online submission

- Rigorous peer review

- Open access: articles freely available online

- High visibility within the field

- Retaining the copyright to your article

Submit your next manuscript at $\boldsymbol{\nabla}$ springeropen.com 